Portland State University

PDXScholar

\title{
Attachment, Well-Being, and College Senior Concerns About the Transition Out of College
}

Joel A. Lane

Portland State University, lanejoel@pdx.edu

Follow this and additional works at: https://pdxscholar.library.pdx.edu/coun_fac

Part of the Counseling Psychology Commons, Counselor Education Commons, and the Student Counseling and Personnel Services Commons

Let us know how access to this document benefits you.

\section{Citation Details}

Lane, Joel A., "Attachment, Well-Being, and College Senior Concerns About the Transition Out of College" (2014). Counselor Education Faculty Publications and Presentations. 33.

https://pdxscholar.library.pdx.edu/coun_fac/33

This Post-Print is brought to you for free and open access. It has been accepted for inclusion in Counselor Education Faculty Publications and Presentations by an authorized administrator of PDXScholar. Please contact us if we can make this document more accessible: pdxscholar@pdx.edu. 
Attachment, Well-Being, and College Senior Concerns About the Transition Out of College Joel A. Lane

Oakland University

Author Note:

Joel A. Lane, Department of Counseling, Oakland University.

Joel A. Lane is now at the Department of Counselor Education, Portland State University.

This research was supported in part by the Oakland University Graduate Student

Research Award.

Correspondence concerning this article should be addressed to Joel A. Lane, Department of Counselor Education, Portland State University, Graduate School of Education, P. O. Box 751, 615 SW Harrison, Room 504 A, Portland OR 97207. E-mail: lanejoel@pdx.edu 


\begin{abstract}
This study examined the relationships among attachment, psychological well-being (PWB), life satisfaction, and concerns about the transition out of college among a sample of college seniors. A path analysis was conducted predicting that PWB and life satisfaction would mediate the relationships between attachment and three types of graduation transition concerns: career, change and loss, and support. Significant mediation effects impacting career concerns and change and loss concerns were discovered. Implications for college counseling are discussed. Keywords: attachment, college graduation, transition.
\end{abstract}


Attachment, Well-Being, and College Senior Concerns About the Transition Out of College

It is widely accepted that the college experience is a time of significant development with regard to identity (Chickering \& Reisser, 1993) and autonomy (Kenyon \& Koerner, 2009). It is also often a time of increased leisure activities and moratorium from adult responsibilities (Sherrod, Haggerty, \& Featherman 1993). As such, college students are free to engage in identity exploration and experimentation without the pressures of having to commit to firm decisions (Lemme, 2006). The senior year of college, then, represents a significant transition, during which individuals prepare to leave behind the freedom of the college experience and to assume ownership of adult roles (Hunter, Keup, Kinzie, \& Maietta, 2012). Despite the significance of this transition, it has received little empirical attention, particularly when compared to the extensive body of research detailing the psychological impact of the first year of college (e.g., Wei, Russell, \& Zakalik, 2005). A frequent focus of first year transition literature has been on the important facilitating role of attachment relationships in providing students with a secure base of support from which to explore and adjust to college life (e.g., Kenny, 1987; Wei et al., 2005); based on this association, the present study explored the extent to which attachment dimensions similarly impact the transition out of college.

\section{The Transition Out of College}

Existing conceptual literature has described the transition out of college as a turning point with considerable implications for functioning and well-being (Gardner, 1998; Lane, 2013b). In support of this position, a small but growing body of qualitative research has empirically identified increasingly ambivalent and negative attitudes among college seniors regarding the transition out of college. For example, a sample of first-generation college seniors reported, in part, the experience of anxiety due to not being able to anticipate coming changes in priorities 
(Overton-Healy, 2010). College seniors have also described fearing both the unknowns associated with exiting college life and also the pressures of developing career plans and becoming financially independent (Yazedjian, Kielaszek, \& Toews, 2010). Such fears seem warranted, as college graduates often experience considerable difficulties adjusting to life after college (Perrone \& Vickers, 2003). Those who are able to secure employment experience significant culture changes (Wendlandt \& Rochlen, 2008) and are susceptible to frustrations with adjusting to new learning curves and little structure (Polach, 2004). Those who are unsuccessful in securing employment experience stagnation and have described the first year after graduation as a low point in their lives (Perrone \& Vickers, 2003). These qualitative studies make useful contributions to conceptualizing the challenges of the graduation transition. Examining this transition using quantitative methodology, however, remains as a gap in existing literature. Part of the complexity involving life transitions is that they generally involve both anticipated and unanticipated changes (Anderson, Goodman, \& Schlossberg, 2012). It would seem that this concept applies to the transition out of college as well. For example, most seniors can reasonably anticipate that the end of college necessitates seeking employment or graduate school; however, graduation involves unanticipated transitions as well, such as losing the structure afforded by the student lifestyle, leaving behind social networks, and feeling pressured by societal expectations that graduates assimilate adult roles (Lane, 2013b). Thus, leaving college represents a significant and multifaceted transition process (Overton-Healy, 2010).

This latter point is particularly relevant considering the framework of emerging adulthood (Arnett, 2004), which was articulated partly to explain the delayed progression into adult roles commonly experienced by traditional-aged college students. Transitions normatively experienced during emerging adulthood (e.g., leaving home) are critical periods for well-being 
(Lane, 2013a; Weiss, Freund, \& Wiesse, 2012). While many emerging adults are able to seamlessly progress through the numerous life and role changes, others experience identity crisis and distress in response to these changes (Buhl, 2007). Moreover, this age group often engages in risky and impulsive behaviors (e.g., binge drinking) to cope with distress (Scott-Parker, Watson, King, \& Hyde, 2011). Collectively, these ideas further underscore the importance of increased attention regarding the transition out of college.

While the graduation transition is lacking in empirical literature, a wealth of research has accumulated regarding facilitative factors in the first year of college. Repeatedly, these studies have identified the importance of attachment relationships. Secure attachments among freshmen have been associated with social competence (Wei et al., 2005), assertiveness (Kenny, 1987), feeling supported in times of stress (Kenny, 1987), and separation-individuation (Mattanah, Hancock, \& Brand, 2004). Conversely, insecure attachments predict freshman loneliness and depression (Wei et al., 2005). Though these findings have not yet been applied to the transition out of college, it is possible that attachment theory is equally salient for both transitions.

\section{Attachment Theory}

Attachment theory (Bowlby, 1969/1982) contends that the relationships we develop with caregivers beginning in infancy inform our attitudes toward help-seeking and new learning in times of distress across the lifespan. The quality of such relationships manifests in internal beliefs regarding the relative capability of both self and others. Thus, several attachment styles are possible: individuals can be either securely attached (i.e., positive views of self and other) or possess one of several insecure attachment strategies, of which anxious (i.e., negative views of self, positive views of others) and avoidant (i.e., positive views of self, negative views of others) are most prominent (Brennan, Clark, \& Shaver, 1998). As a result of these representations, 
anxiously-attached individuals are prone to seek interpersonal enmeshment, while avoidantattached individuals are likely to seek interpersonal isolation (Mallinckrodt, 2000). These attachment strategies are theorized to become activated during times of distress (Fraley \& Davis, 1997), thereby impacting one's ability to positively resolve the distressing situation and, ultimately, influencing well-being. Support for this theory has been demonstrated in a sample of emerging adults experiencing various life transitions (Lane, 2013a). Specifically, attachment security was predictive of both psychological well-being (PWB) and life satisfaction.

This latter point positions insecure attachment strategies as a self-reinforcing mechanism. That is, negative beliefs regarding self and/or other are activated during times of transition, diminishing one's ability to effectively cope with the stress of the transition and reinforcing the negative attachment feelings (Fraley \& Davis, 1997). When considered in the college context, it is possible that the aforementioned impact of attachment on the freshman transition would continue throughout the college experience, interfering with key college student development outcomes. Such outcomes include emotional regulation, mature interpersonal relationships, identity, and purpose (Chickering \& Reisser, 1993), factors that are all impacted by attachment (Brennan et al., 1998). These problems could be compounded during the graduation transition, during which securely attached seniors could rely on healthy interpersonal functioning, while insecurely attached seniors would feel ill-prepared given the unresolved distress from previous transitions. Thus, a plausible sequence of relationships would be for attachment to impact wellbeing, which would impact attitudes regarding the graduation transition.

Such a possibility has never been tested, though doing so would be of utility to the college counseling profession. Understanding how attachment predicts well-being and graduation-related distress could aid college counselors in conceptualizing and working with 
individuals engaged in this transition. This line of inquiry could also provide some basis for comparing the transition out of college to other emerging adult transitions to which more attention has been given (e.g., Lane, 2013a; Wei et al., 2005).

\section{Present Study}

The present study examined the roles of attachment, PWB, and life satisfaction in attitudes regarding the transition out of college. Because PWB is conceptually and empirically predictive of happiness and life satisfaction (Keyes, Ryff, \& Shmotkin, 2002), it was predicted that attachment would contribute to PWB, which, in turn, would contribute to satisfaction with life. Given the ambivalent and negative attitudes that college seniors reported in the aforementioned qualitative research, it is possible that this sequence of constructs informs beliefs among college seniors regarding their ability to successfully transition into life after college. That is, perhaps attachment insecurity among college students would contribute to reduced PWB as individuals unsuccessfully resolve stressful situations (Fraley \& Davis, 1997). Reduced PWB would contribute to diminished life satisfaction (Keyes et al., 2002), culminating in increased concern regarding their ability to develop a satisfying life after college. These ideas were expressed as a path model in which the following hypotheses were established:

Hypothesis 1: Attachment anxiety and attachment avoidance would be negatively related to PWB and life satisfaction, and positively related to the various domains of graduation-related concerns.

Hypothesis 2: Life satisfaction would mediate the relationships between the attachment dimensions and the graduation-related concerns.

Hypothesis 3: PWB would mediate the relationships between the attachment dimensions and life satisfaction. 


\section{Method}

\section{Participants and Procedure}

The sample consisted of traditional-aged college seniors enrolled at a medium-sized University in a suburban area of the Midwest. Participants were recruited during class sessions and completed surveys in either a paper or electronic format, depending on the classroom format (both versions of the surveys were identical). The sample $(N=182)$ was comprised of students majoring in either Psychology $(n=90)$ or Education $(n=92)$. Participants were predominantly White $(90.7 \%)$ and female $(79.7 \%)$, and ranged in age from 20 to $29(M=22.50, S D=1.81)$.

\section{Instruments}

Attachment. Attachment was measured using the Experiences in Close Relationships Scale- Short Form (ECR-S; Wei, Russell, Mallinckrodt, \& Vogel, 2007). The ECR-S is a 12item self-report measure derived from the original 36-item Experiences in Close Relationships Scale (Brennan et al., 1998). Its items utilize a seven-point scale $(1=$ strongly disagree, $7=$ strongly agree) in assessing participant agreement with statements of romantic relationship patterns. The items are evenly divided into two subscales that orthogonally measure attachment anxiety (e.g., "I worry that romantic partners won't care about me as much as I care about them") and attachment avoidance ("I am nervous when partners get too close to me"). Each subscale has a possible scoring range of 6-42, with higher scores indicating higher attachment anxiety or avoidance, respectively. The authors reported strong factor structure and acceptable internal consistency estimates derived from several large, undergraduate samples (Wei et al., 2007).

Psychological Well-Being (PWB). PWB was assessed using the World Health Organization-Five Well-Being Index (WHO-5; Bech, Olsen, Kjoller, \& Rasmussen, 2003). Each of its five items is a positively-worded self-statement pertaining to mood and energy (e.g., "I 
have felt calm and relaxed"). Participants use a 6-point scale $(0=$ Not present, $5=$ Constantly present) to rate the presence of the emotion over a 2-week period. Item scores are summed and multiplied by four, resulting in a possible scoring range of 0-100. Scores below 50 indicate poor well-being and scores below 28 indicate depression. The WHO-5 has been demonstrated to be unidimensional and to possess adequate internal consistency (Bech et al., 2003).

Life Satisfaction. The 5-item Satisfaction with Life Scale (SWLS; Diener, Emmons, Larsen, \& Griffin, 1985) was used to assess life satisfaction. The items contain self-statements (e.g., "In most ways my life is close to my ideal") rated on a 7-point scale $(1=$ strongly disagree, 7 = strongly agree). The item responses are summed, resulting in a possible scoring range of 535, with higher scores indicating higher life satisfaction. The authors reported strong internal consistency $(\alpha=.87)$ and 2-month test retest reliability (.82), and SWLS scores were highly correlated with other measures of life satisfaction (Diener et al., 1985).

Graduation-Related Concerns. Graduation concerns were measured using the 31-item Senior Concerns Survey- Short Form (SC-S; Taub, Servaty-Seib, \& Cousins, 2006). The SC-S items ask participants to rate their degree of concern on a 4 -point scale $(1=$ no concern, $4=$ major concern) and pertain to four subscales: 1) career-related concerns (9-items; e.g., “Adhering to new workplace policies"); 2) change and loss-related concerns (8-items; e.g., "Not being able to hang out with friends after graduation"); 3) graduate school-related concerns (6items; e.g., "What to do if I am not accepted into graduate school”); and 4) support-related concerns (8-items, e.g., "Having to make sacrifices to be near my family or a significant other"). The item responses are summed for each subscale, with higher scores indicating higher degrees of concern. In an effort to reduce the effect of confounds in the present study, the graduate school-related concerns subscale was not included in the data analysis since an independent 
samples $t$ test revealed significant differences depending on whether or not individuals in the sample were planning on attending graduate school $(t[178]=-4.846, p=.000)$. Taub et al. (2006) reported internal consistencies of .85 (career), .85 (change and loss), and .73 (support).

\section{Data Analysis}

A path analysis was conducted using Amos 21.0 (Arbuckle, 2012) to test the hypotheses. A theoretical mediation model was developed depicting the relationships among the study variables. Specifically, paths were drawn connecting: 1) attachment anxiety and attachment avoidance to PWB; 2) attachment anxiety, attachment avoidance, and PWB to life satisfaction; and 3) attachment anxiety, attachment avoidance, and life satisfaction to career concerns, change and loss concerns, and support concerns. Because Taub et al. (2006) reported gender differences on the SC-S career concerns subscale, gender was controlled for by drawing a path from gender to the career concerns variable. Additionally, well-being has been found to increase with age throughout emerging adulthood (Galambos, Barker, \& Krahn, 2006). Thus, age was controlled for by drawing paths from age to both life satisfaction and PWB.

With respect to Hypothesis 1, a direct path model (Model a) was tested so that the direct impact of each attachment variable on PWB, life satisfaction, and the graduation concern variables could be examined. To test Hypothesis 2, which referred to the mediating effect of life satisfaction, paths were added to the direct path model connecting life satisfaction to each of the graduation concern variables (Model b). Hypothesis 3, which referred to the mediating effect of PWB, was tested using the full theoretical mediation model, which was created by adding a path connecting PWB to life satisfaction (Model c). The fit of each model was compared using a) the chi-square goodness of fit test $\left(\chi^{2}\right)$, with smaller, insignificant values being preferable; b) the root mean square error of approximation (RMSEA), which should be lower than .08; and c) the 
comparative fit index (CFI), which should exceed .95 (Quintana \& Maxwell, 1999).

The significance of the mediation effects was tested using a bias-corrected bootstrap analysis (Shrout \& Bolger, 2002). This method evaluates significance by generating 95\% confidence intervals of the indirect effects through repeatedly sampling the data set to test the model. The results are bias-corrected in that the estimate is not necessarily the midpoint of the confidence interval. The analysis was set to execute 10,000 bootstrapped samples. Because the confidence intervals are bias-corrected, this method of examining mediation effects offers greater statistical power with respect to other methods (Shrout \& Bolger, 2002).

\section{Results}

\section{Data Screening and Transformation}

Data were screened for univariate and multivariate outliers and assumptions of normality, linearity, and homogeneity of variance (Meyers, Gamst, \& Guarino, 2006). Following the recommendations of Meyers et al. (2006), univariate outliers were transformed using winsorization to equal the nearest acceptable bound. This procedure was applied to two ECR-S attachment anxiety subscale cases, two WHO-5 cases, four SC-S change and loss subscale cases, and three SC-S support subscale cases. The initial three columns of Table 1 display the resulting descriptive statistics for each instrument scale. Following transformation, each scale was normally distributed (Meyers et al., 2006), and all multivariate assumptions held.

\section{Preliminary Covariate and Correlational Analyses}

In addition to the descriptive statistics, Table 1 presents correlations among all study and control variables. As expected, attachment anxiety was significantly related in the hypothesized directions to PWB, life satisfaction, and the graduation concern variables. Attachment avoidance was significantly related in the hypothesized directions to PWB, life satisfaction, and the change 
and loss concerns variable, but was not related to the other graduation concern variables. PWB and life satisfaction were strongly correlated with one another $(r=.72)$, and both were negatively related to each of the graduation concern variables. Finally, the graduation concern variables were all significantly related, with intercorrelations ranging from .50 to .65 .

Regarding the control variables, gender and attachment avoidance were significantly related. That is, being male was associated with higher avoidance scores. Additionally, age was negatively associated change and loss related concerns. Because of this significant relationship, a path was added to the model to connect age to loss concerns. No path was added to connect gender and attachment avoidance since the attachment variables were exogenous and did not need to be controlled for. No other associations were found involving the control variables.

\section{Direct Path Model Analysis}

In all models estimated, the ratio of the number of cases to the number of free parameters exceeded 10:1 (Kline, 2005). Hypothesis 1 was tested using Model a. The model yielded a poor fit to the data $\left(\chi^{2[17]}=138.98, p=.000, \mathrm{RMSEA}=.199, \mathrm{CFI}=.743\right)$. However, the direct effects from both attachment anxiety and attachment avoidance to $\operatorname{PWB}(\beta=-.33$ and $\beta=-.21$, respectively) and to life satisfaction $(\beta=-.41$ and $\beta=-.25$, respectively) were significant at the $p$ $<.01$ level or higher. Attachment anxiety was significantly related in the hypothesized directions to career related concerns $(\beta=.27, p<.01)$, change and loss related concerns $(\beta=.37, p<.001)$, and support related concerns $(\beta=.34, p<.001)$. Attachment avoidance, however, was significantly related to change and loss related concerns $(\beta=.17, p<.05)$, but not to the other graduation concern variables. Thus, Hypothesis 1 was partially supported.

\section{Mediation Model Analyses}

Next, the mediation models were tested. Hypothesis 2 was tested using Model b, which 
added parameters from life satisfaction to each of the graduation concern variables. Model $b$ provided a poor fit to the data $(\chi 2[16]=56.94, p=.000, \mathrm{RMSEA}=.119, \mathrm{CFI}=.914)$. Its fit, however, was significantly better than that of Model a $(\chi 2[1]=82.04, p=.000)$. The indirect effects of attachment anxiety and attachment avoidance on career related concerns through life satisfaction $(\beta=.080$ and $\beta=.046$, respectively) were significant at the $p<.01$ level or higher. The direct relationship between attachment anxiety and career related concerns, which was significant in the direct effects model $(\beta=.27, p<.01)$, was no longer significant after accounting for life satisfaction $(\beta=.11)$. Additionally, the indirect effects of attachment anxiety and attachment avoidance on change and loss related concerns through life satisfaction $(\beta=.034$ and $\beta=.019)$ were significant at the $p<.05$ level. The impact of attachment avoidance on change and loss concerns, while significant in the direct effects model $(\beta=.17, p<.05)$, was rendered insignificant after accounting for life satisfaction $(\beta=.13)$. Attachment anxiety, on the other hand, was still significantly related to change and loss concerns after accounting for life satisfaction $(\beta=.31, p<.001)$; however, this relationship represented a $16 \%$ reduction with respect to the same relationship tested in Model a $(\beta=.37, p<.001)$. Neither of the other indirect effects involving the support related concern variable was significant. Hypothesis 2, therefore, was partially supported.

Hypothesis 3 was then tested using Model c, which was created by adding a path from PWB to life satisfaction. This model was an excellent fit to the data $(\chi 2[14]=18.77, p=.17$, RMSEA $=.043, \mathrm{CFI}=.990)$. Model fit was significantly improved with respect to both Model a $(\chi 2[3]=120.21, p=.000)$ and Model $\mathrm{b}\left(\chi^{2}[2]=38.17, p=.000\right)$. The indirect effects of attachment anxiety and attachment avoidance on life satisfaction through $\mathrm{PWB}(\beta=-.198$ and $\beta$ $=-.127$, respectively) were each significant at the $p<.01$ level or higher. Thus, Hypothesis 3 
was supported. The direct effects of attachment anxiety and attachment avoidance on life satisfaction from the testing of Model a $(\beta=-.41$ and $\beta=-.25$, respectively) were each reduced by roughly half after accounting for $\operatorname{PWB}(\beta=-.22$ and $\beta=-.12$, respectively).

Table 2 provides a summary of all mediation effects in the present model. The table demonstrates that seven indirect effects were statistically significant and four were not. Though not part of the present study's hypotheses, the indirect effect of PWB on career-related concerns through life satisfaction was significant $(\beta=-.221, p<.001)$, while the indirect effect of PWB on change and loss related concerns through life satisfaction approached significance $(\beta=-.092, p=$ .063). These findings suggested that psychological health among college seniors impacted their satisfaction with life, which in turn impacted their career-related concerns.

The results of testing Model $\mathrm{c}$ are presented in Figure 1. In the interest of parsimony, the control variables (i.e., gender and age) are not included in the figure. In this model, gender was significantly and positively related to career concerns $(\beta=-.13, p<.05)$, indicating that females reported higher levels of concern. Additionally, age was significantly and negatively related to life satisfaction $(\beta=-.11, p<.05)$, as expected, as well as to change and loss concerns $(\beta=-.18$, $p<.001)$. Overall, the model explained $18 \%$ of the variance in career concerns, $24 \%$ of the variance in change and loss concerns, and $13 \%$ of the variance in support concerns.

\section{Alternative Model Testing}

Because of the cross-sectional nature of the study, an alternative model (Model d) was tested in which the parameters among the endogenous variables in the study were reversed. Doing so allowed for comparisons to be made between the hypothesized model and another model that could potentially explain the relationships among the study variables. Model d posited that attachment predicted graduation concerns, which, in turn, predicted PWB. PWB, in 
turn, predicted life satisfaction. Essentially, elevated attachment anxiety and/or avoidance would result in elevated graduation distress, and this distress would result in reduced psychological health, which, in turn, would result in reduced life satisfaction. Model d did not provide an adequate fit to the data $(\chi 2[14]=34.66, p=.002, \mathrm{RMSEA}=.090, \mathrm{CFI}=.956)$.

\section{Discussion}

The present study tested a model positing the mechanism through which attachment influences the transition-related concerns of college seniors. Life satisfaction significantly mediated the relationships of attachment anxiety and avoidance on two of the domains of graduation concern (i.e., career concerns and change and loss concerns), but did not mediate their respective impacts on support concerns. Moreover, PWB significantly mediated the relationships of each attachment variable on life satisfaction.

The present study contributes quantitative evidence corroborating existing graduation literature, which had qualitatively identified the difficult periods of adjustment and negative attitudes surrounding college graduation (Overton-Healy, 2010; Perrone \& Vickers, 2003; Yazedjian et al., 2010). The strongest relationships to PWB and life satisfaction were found with career-related and loss-related graduation concerns, suggesting that college senior well-being is moderately tied to these aspects of the transition. This finding is reminiscent of those reported by Yazedjian et al. (2010). Specifically, their sample reported numerous graduation-related concerns, but those pertaining to the transition into career life were the most salient.

Moreover, the present findings support the contention that attachment security is a key element in the degree of distress college seniors feel toward the transition out of college. While this finding had not been proposed prior to the present study, it confirms that the impact of attachment on the graduation transition is similar to its impact on other emerging adult 
transitions (Buhl, 2007; Lane, 2013a). These relationships suggest that insecure attachments namely, doubting either one's own capabilities or the ability of others to be helpful in the face of challenging situations - contribute to college senior worries about their ability to secure stable careers, overcome the changes and losses of leaving college behind, and develop new support networks outside of the college environment.

Interestingly, the impact on each domain of graduation concern was larger for attachment anxiety than for attachment avoidance. This finding suggests that negative representations of self are more detrimental with regard to graduation concerns than are negative representations of others (i.e., anxious vs. avoidant attachment; Brennan et al., 1998). It is possible that the reason for this difference is that individuals with avoidant attachment styles seem to actively repress attachment feelings and to lack emotional awareness (Fraley \& Davis, 1997). Such individuals, then, may be prone to reporting fewer concerns due to a lack of insight regarding the true amount of distress they are experiencing. Such a possibility, however, requires further testing.

As expected, life satisfaction accounted for a significant portion of the relationships among the attachment variables and two of the three graduation concern variables. This finding supports the hypothesis that securely-attached college students are able to develop and maintain satisfying lives during college, giving them confidence regarding their ability to do the same in their lives after college. It is important to note, however, that the magnitude of each statistically significant indirect effect was relatively small. Moreover, for each attachment variable, the indirect effect predicting career concerns was over twice as strong as the indirect effect predicting change and loss concerns. This finding can be interpreted two ways. Perhaps it is an indication, as many have suggested, that concerns about transitioning into career-life are the most psychologically salient concerns for seniors (Taub et al., 2006), as evidenced by the strong 
association of life satisfaction and the career concerns variable. Or, it may also be that change and loss concerns share a stronger direct relationship with attachment, preventing life satisfaction from functioning as a mediating variable.

Hypothesis 2 was only partially supported, however, because neither relationship among the attachment variables and support concerns were mediated. While both attachment variables and life satisfaction were significantly related to support concerns in the initial correlational analysis, only attachment anxiety was significantly related when all three were concurrently regressed onto support concerns in the mediation model analysis. Though this finding contradicted Hypothesis 2, it makes sense on the basis that attachment anxiety is associated with low social self-efficacy and interpersonal dependence (Mallinckrodt \& Wei, 2005), as these individuals doubt their abilities to handle adversity and believe they must be overly reliant on others to do so. As such, anticipating the changing of support systems would be a particularly salient concern for individuals with elevated attachment anxiety, making the direct relationship among these variables resistant to mediation effects, as was the case in the present study.

With regard to Hypothesis 3, which referred to the mediating effect of PWB on the relationships among attachment anxiety and avoidance on life satisfaction, both indirect effects were significant. This finding supports previous research examining the role of attachment on well-being and life satisfaction during life transition in emerging adulthood (Lane, 2013a). The mediation effect suggests that individuals with elevated attachment insecurity experience comparatively less PWB, culminating in diminished life satisfaction. The indirect effects predicting life satisfaction were notably robust, particularly in comparison to the aforementioned indirect effects predicting graduation concern. Thus, attachment appears to be a major factor in the ability of college students to develop psychologically healthy, satisfying lives. 
Interestingly, PWB also indirectly contributed to career concerns. That is, individuals who were high in PWB reported higher life satisfaction, resulting in greater confidence about the ability to successfully transition into career-life. This finding supports the prior assertion that career-related concerns are the most psychologically relevant domain of concern seniors experience as they prepare to transition out of college.

\section{Limitations}

Despite the efforts taken to reduce confounding variables in the present study, several limitations remain. The primary of these limitations is the cross-sectional, non-experimental research design. In an effort to circumvent this limitation, the present study tested an alternative model, which was determined to provide a significantly worse fit to the data than the primary mediation model. Nevertheless, it would be presumptuous to conclude that the present model is definitive with regard to the sequential paths among variables. Additionally, the findings are limited by the demographics of the sample, of which a disproportionate amount were Caucasian $(90.7 \%)$ and female (79.7\%). Moreover, the sample was limited to students majoring in Psychology and Education, two undergraduate degree areas facing uncertain job prospects, which could have affected their feelings about life after college.

\section{Implications for College Counselors}

The present findings have utility for university counselors working with college seniors. Based on these findings, attachment theory seems to provide conceptual insights regarding the graduation transition. That is, seniors with elevated attachment anxiety reported higher careerrelated, loss-related, and support-related graduation concerns, while those with elevated attachment avoidance reported higher loss-related graduation concerns. Accordingly, given that attachment anxiety equates to negative beliefs regarding self and positive beliefs regarding others 
(Brennan et al., 1998), counselors working with distressed seniors could attempt to strengthen self-concept as a means of resolving graduation concerns. Similarly, seniors presenting with concerns related to the changes and losses of graduation - which were significantly related to both attachment dimensions - may be well served by this intervention strategy or by interventions that target utilization of external support resources, since attachment avoidance is characterized by negative beliefs regarding the helpfulness of others (Brennan et al., 1998).

College counselors should also be mindful of the difficulties that insecure attachment strategies pose to the therapeutic relationship (Fraley \& Davis, 1997) and anticipate how those difficulties may interfere with counseling distressed seniors. Mallinckrodt (2000) suggested utilizing the inherent transference and countertransference of the therapeutic relationship as a corrective attachment experience for insecurely attached clients. Given the present findings, this suggestion might be of use to college counselors working with college seniors who are negatively impacted by the graduation transition. That is, the corrective attachment experiences afforded by the therapeutic relationship may help resolve insecure attachments and, therefore, may also help resolve concerns about leaving college.

\section{Implications for Future Research}

Future research efforts should be devoted to confirming the findings with a more representative sample. Additionally, future studies should test additional mediating factors in the present model as a means of further understanding the model's associations. Doing so would advance an understanding of the specific mechanisms by which attachment affects the graduation transition. Finally, future research should consider the refinement of the SC-S given that present study could only utilize three of the four subscales. Collectively, such efforts would allow researchers to better understand how best to facilitate the transition out of the college experience. 


\section{References}

Anderson, M. L., Goodman, J., \& Schlossberg, N. K. (2012). Counseling adults in transition: Linking Schlossberg's theory with practice in a diverse world. ( $4^{\text {th }}$ ed.). New York: Springer.

Arbuckle, J. L. (2012). Amos (Version 21.0) [Computer Program]. Chicago: SPSS.

Arnett, J. J. (2004). Emerging adulthood: The winding road from the late teens through the twenties. New York: Oxford University Press.

Bech, P., Olsen, L. R., Kjoller, M., \& Rasmussen, N. K. (2003). Measuring well-being rather than the absence of distress symptoms: A comparison of the SF-36 Mental Health subscale and the WHO-Five Well-Being Scale. International Journal of Methods in Psychiatric Research, 12(2), 85-91.

Bowlby, J. (1969/1982). Attachment and loss: Vol. 1. Attachment. New York: Basic Books.

Brennan, K. A., Clark, C. L., \& Shaver, P. R. (1998). Self-report measurement of adult attachment: An integrative overview. In J. A. Simpson \& W. S. Rholes (Eds.), Attachment theory and close relationships (pp. 46-76). New York: Guilford Press.

Buhl, H. M. (2007). Well-being and the child-parent relationship at the transition from university to work life. Journal of Adolescent Research, 22(5), 550-571.

Chickering, A. W., \& Reisser, L. (1993). Education and identity ( $2^{\text {nd }}$ ed.). San Francisco, CA: Jossey-Bass.

Diener, E., Emmons, R. A., Larsen, R. J., \& Griffin, S. (1985). The Satisfaction With Life Scale. Journal of Personality Assessment, 49(1), 71-75.

Fraley, R. C., \& Davis, K. E. (1997). Attachment formation and transfer in young adults' close friendships and romantic relationships. Personal Relationships, 4(2), 131-144. 
Galambos, N. L., Barker, E. T., \& Krahn, H. J. (2006). Depression, self-esteem, and anger in emerging adulthood: Seven-year trajectories. Developmental Psychology, 42(2), 350-365.

Gardner, J. N. (1998). The Senior year experience: Facilitating integration, reflection, closure and transition. San Francisco, CA: Jossey-Bass.

Hunter, M. S., Keup, J. R., Kinzie, J., \& Maietta, H. (Eds.) (2012). The senior year: Culminating experiences and transitions. Columbia, SC: National Resource Center: First-Year Experience and Students in Transition.

Kenny, M. E. (1987). The extent and function of parental attachment among first-year college students. Journal of Youth and Adolescence, 16(1), 17-27.

Kenyon, D. B., \& Koerner, S. S. (2009). Examining emerging-adults' and parents' expectations about autonomy development during the transition to college. Journal of Adolescent Research, 24(3), 293-320.

Keyes, C. L. M., Ryff, C. D., \& Shmotkin, D. (2002). Optimizing well-being: The empirical encounter of two traditions. Journal of Personality and Social Psychology, 82(6), 10071022.

Kline, R. B. (2005). Principles and practice of structural equation modeling (2 ed.). New York: The Guilford Press.

Lane, J. A. (2013a). Attachment, social support, and well-being during life transition in emerging adulthood. Manuscript submitted for publication.

Lane, J. A. (2013b). Group counseling for students transitioning out of postsecondary education: A narrative approach. Groupwork: An Interdisciplinary Journal for Working With Groups, 23(1), 34-55.

Lemme, B. (2006). Development in adulthood (4th ed.). New York: Pearson Education, Inc. 
Mallinckordt, B. (2000). Attachment, social competencies, social support, and interpersonal process in psychotherapy. Psychotherapy Research, 10(3), 239-266.

Mallinckrodt, B., \& Wei, M. (2005). Attachment, social competencies, social support, and psychological distress. Journal of Counseling Psychology, 52(3), 358-367.

Mattanah, J. F., Hancock, G. R., \& Brand, B. L. (2004). Parental attachment, separationindividuation, and college student adjustment: A structural equation analysis of meditational effects. Journal of Counseling Psychology, 51(2), 213-225.

Meyers, L. S., Gamst, G., \& Guarino, A. J. (2006). Applied multivariate research: Design and interpretation. Thousand Oaks, CA: Sage Publications.

Overton-Healy, J. (2010). First-Generation College Seniors: A phenomenological exploration of the transitional experience of the final college year. (Doctoral dissertation, Indiana University of Pennsylvania). Retrieved from dspace.iup.edu/bitstream/handle/2069/249/Julia Overton-Healy.pdf?sequence=1

Perrone, L., \& Vickers, M. H. (2003). Life after graduation as a "very uncomfortable world”: An Australian case study. Education and Training, 45(2), 69-78.

Polach, J. L. (2004). Understanding the experience of college graduates during their first year of employment. Human Resource Development Quarterly, 15(1), 5-23.

Quintana, S. M., \& Maxwell, S. E. (1999). Implications of recent developments in structural equation modeling for counseling psychology. The Counseling Psychologist, 27, 485527.

Scott-Parker, B., Watson, B. C., King, M. J., \& Hyde, M. K. (2011). The psychological distress of the young driver: A brief report. Injury Prevention, 17(4), 275-277. 
Sherrod, L. R., Haggerty, R. J., \& Featherman, D. L. (1993). Introduction: Late adolescence and the transition to adulthood. Journal of Research on Adolescence, 3(3), 217-226.

Shrout, P. E., \& Bolger, N. (2002). Mediation in experimental and non-experimental studies: New procedures and recommendations. Psychological Methods, 7(4), 422-445.

Taub, D. J., Servaty-Seib, H. L., and Cousins, C. (2006). On the brink of transition: The concerns of college seniors. Journal of the First-Year Experience and Students in Transition, 18(2), 111-132.

Wendlandt, N. M., \& Rochlen, A. B. (2008). Addressing the college-to-work transition: Implications for university career counselors. Journal of Career Development, 35(2), $151-165$.

Wei, M., Russell, D. W., Mallinckrodt, B., \& Vogel, D. L. (2007). The Experiences in Close Relationship Scale (ECR)-Short Form: Reliability, validity, and factor structure. Journal of Personality Assessment, 88, 187-204.

Wei, M., Russell, D. W., \& Zakalik, R. A. (2005). Adult attachment, social self-efficacy, selfdisclosure, loneliness, and subsequent depression for freshman college students: A longitudinal study. Journal of Counseling Psychology, 52(4), 602-614.

Weiss, D., Freund, A. M., \& Wiesse, B. S. (2012). Mastering developmental transitions in young and middle adulthood: The interplay of openness to experiences and traditional gender ideology on women's self-efficacy and subjective well-being. Developmental Psychology, 48(6), 1774-1784.

Yazedjian, A., Kielaszek, B. J., \& Toews, M. L. (2010). Students' perceptions regarding their impending transition out of college. Journal of the First-Year Experience \& Students in Transition, 22(2), 33-48. 
Table 1

Descriptive Statistics and Pearson Intercorrelations Among Study and Control Variables

\begin{tabular}{|c|c|c|c|c|c|c|c|c|c|c|c|}
\hline \multirow[t]{2}{*}{ Variables } & \multicolumn{3}{|c|}{ Descriptive Statistics } & \multicolumn{8}{|c|}{ Intercorrelations } \\
\hline & $\alpha$ & $M$ & $S D$ & 1 & 2 & 3 & 4 & 5 & 6 & 7 & 8 \\
\hline 1. ECR-S Anxiety & .72 & 21.02 & 6.34 & - & & & & & & & \\
\hline 2. ECR-S Avoidance & .82 & 15.86 & 6.51 & $.26 * * *$ & - & & & & & & \\
\hline 3. WHO-5 & .84 & 57.60 & 19.52 & $-.39 * * *$ & $-.30 * * *$ & - & & & & & \\
\hline 4. SWLS & .90 & 23.93 & 6.97 & $-.48 * * *$ & $-.35 * * *$ & $.72 * * *$ & - & & & & \\
\hline 5. SC-S Career & .84 & 24.85 & 5.48 & $.25^{* *}$ & .01 & $-.27 * * *$ & $-.36^{* * *}$ & - & & & \\
\hline 6. SC-S Change and Loss & .88 & 14.99 & 5.19 & $.42 * * *$ & $.28 * * *$ & $-.25 * *$ & $-.33 * * *$ & $.50 * * *$ & - & & \\
\hline 7. SC-S Support & .73 & 16.91 & 4.52 & $.35 * * *$ & .14 & $-.16^{*}$ & $-.20 * *$ & $.61 * * *$ & $.65 * * *$ & - & \\
\hline 8. Gender & - & - & - & -.08 & $-.20 * *$ & .05 & .11 & .12 & -.05 & .01 & - \\
\hline 9. Age & - & 22.50 & 1.81 & -.01 & -.07 & .01 & -.10 & .10 & $-.20 * *$ & -.09 & -.09 \\
\hline
\end{tabular}

Note: Gender was coded so that $0=$ male, $1=$ female. $* p<.05, * * p<.01, * * * p<.001$. 
Table 2

Bootstrap Analysis of Magnitude and Statistical Significance of Indirect Effects

\begin{tabular}{|c|c|c|c|c|c|c|c|c|}
\hline \multicolumn{2}{|c|}{$\begin{array}{l}\text { Independent } \\
\text { Variable }\end{array}$} & \multicolumn{2}{|c|}{$\begin{array}{l}\text { Mediator } \\
\text { Variable }\end{array}$} & $\begin{array}{l}\text { Dependent } \\
\text { Variable }\end{array}$ & $\begin{array}{c}\beta \text { (standardized path } \\
\text { coefficient and product) }\end{array}$ & $\begin{array}{l}\text { Mean indirect } \\
\text { effect }(B)^{\mathrm{a}}\end{array}$ & $S E$ of mean $^{\text {a }}$ & $\begin{array}{l}95 \% \text { confidence interval } \\
\text { for mean indirect effect }\end{array}$ \\
\hline \multicolumn{9}{|c|}{ Indirect effects hypothesized to be statistically significant } \\
\hline Anxiety & $\rightarrow$ & SWLS & $\rightarrow$ & Career & $(-.23) \times(-.34)=.080^{1}$ & .068 & .025 & .029 to $.130 * * *$ \\
\hline Anxiety & $\rightarrow$ & SWLS & $\rightarrow$ & Loss & $(-.23) \times(-.14)=.034^{1}$ & .027 & .017 & .001 to $.070 *$ \\
\hline Anxiety & $\rightarrow$ & SWLS & $\rightarrow$ & Support & $(-.23) \times(-.03)=.007^{1}$ & .010 & .015 & -.021 to .040 \\
\hline Avoidance & $\rightarrow$ & SWLS & $\rightarrow$ & Career & $(-.14) \times(-.34)=.046^{1}$ & .039 & .017 & .010 to $.080^{* *}$ \\
\hline Avoidance & $\rightarrow$ & SWLS & $\rightarrow$ & Loss & $(-.14) \times(-.14)=.019^{1}$ & .015 & .011 & .000 to $.044^{*}$ \\
\hline Avoidance & $\rightarrow$ & SWLS & $\rightarrow$ & Support & $(-.14) \times(-.03)=.004^{1}$ & .003 & .009 & -.012 to .024 \\
\hline Anxiety & $\rightarrow$ & PWB & $\rightarrow$ & SWLS & $(-.33) \times(.60)=-.198^{2}$ & -.218 & .054 & -.332 to $-.121 * * *$ \\
\hline Avoidance & $\rightarrow$ & PWB & $\rightarrow$ & SWLS & $(-.21) \times(.60)=-.127^{2}$ & -.136 & .044 & -.224 to $-.052^{* *}$ \\
\hline \multicolumn{9}{|c|}{ Indirect effects not hypothesized to be statistically significant } \\
\hline PWB & $\rightarrow$ & SWLS & $\rightarrow$ & Career & $(.60) \times(-.34)=-.221^{2}$ & -.062 & .016 & -.094 to $-.033 * * *$ \\
\hline PWB & $\rightarrow$ & SWLS & $\rightarrow$ & Loss & $(.60) \times(-.14)=-.092^{2}$ & -.024 & .013 & -.051 to .064 \\
\hline PWB & $\rightarrow$ & SWLS & $\rightarrow$ & Support & $(.60) \times(-.03)=-.020^{2}$ & -.005 & .013 & -.030 to .021 \\
\hline
\end{tabular}

Note: SWLS = life satisfaction, PWB = psychological well-being, Career $=$ career related concerns, Loss $=$ change and loss related concerns, Support $=$ support related concerns. ${ }^{a}$ Values based on unstandardized coefficients. ${ }^{1}$ estimated by testing Model $\mathrm{b},{ }^{2}$ estimated by testing Model c. $* p<.05, * * p<.01, * * * p<.001$. 


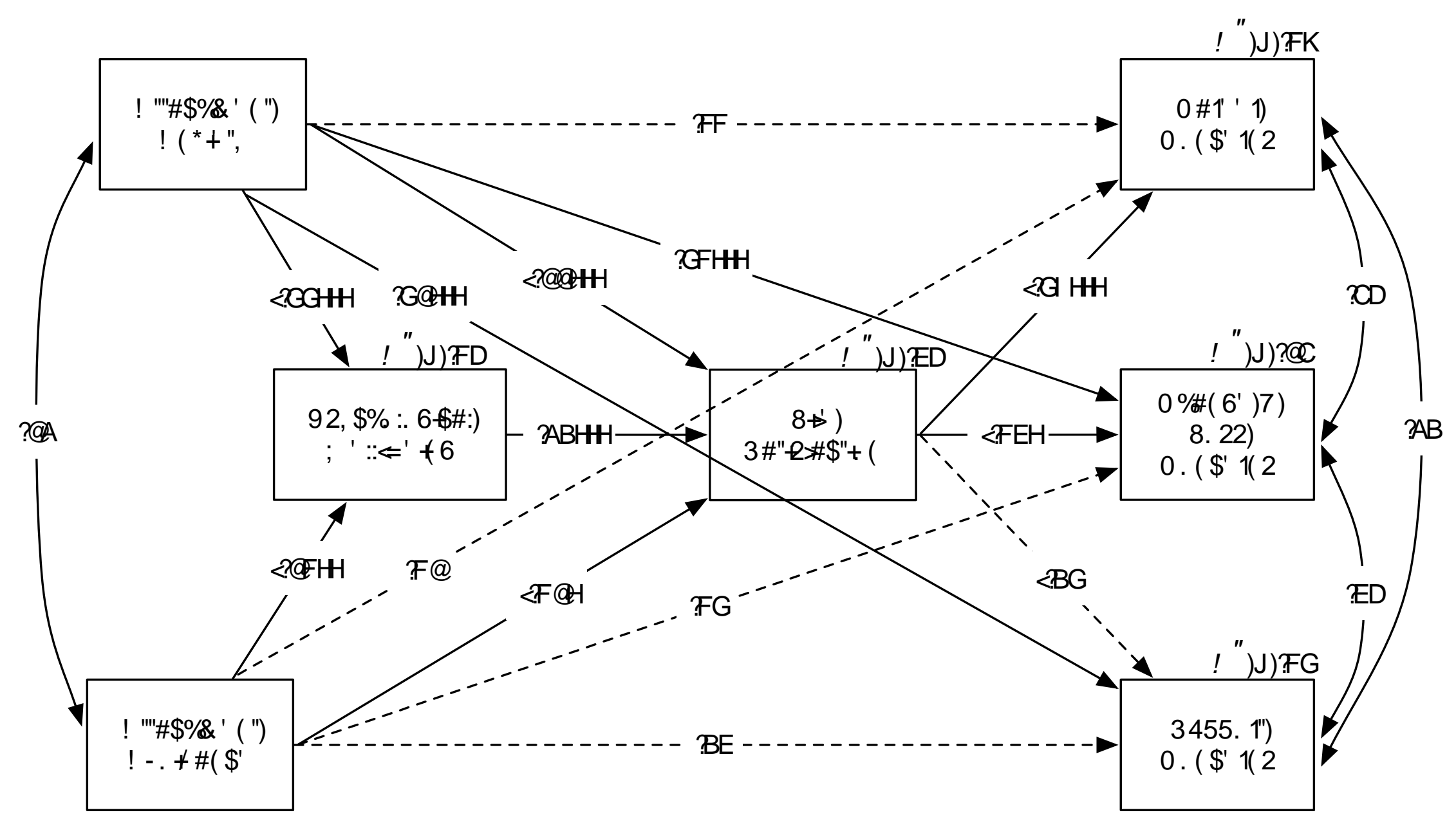

Figure 1. Final model. Dashed lines represent nonsignificant parameters. Gender and age are excluded from the model for parsimony. $* p<.05, * * p<.01, * * * p<.001$. 